Int. J. Dev. Biol. 56: 901-907 (2012)

doi: $10.1387 / \mathrm{ijdb} .130001 \mathrm{et}$

\title{
Strategies to support human oocyte development in vitro
}

\author{
EVELYN E. TELFER* and MARIE MCLAUGHLIN \\ Institute of Cell Biology and Centre for Integrative Physiology, University of Edinburgh, Scotland
}

\begin{abstract}
Many young cancer patients are now being given the option to store ovarian cortical biopsies before undergoing potentially damaging chemo or radio-therapy. This tissue mainly contains large numbers of immature primordial follicles. Currently the only option to restore fertility using this tissue is by transplantation which may not be a viable option for all patients. Greater options to realise the potential of this tissue to restore fertility could be achieved by the development of in vitro systems that support oocyte development. The ability to develop human oocytes from the most immature stages of follicles (primordial) through to maturation and fertilisation in vitro would revolutionise fertility preservation practice. This has been achieved in mouse where in vitro grown (IVG) oocytes from primordial follicles have resulted in the production of live offspring. However, developing IVG systems to support complete development of human oocytes has been more difficult because of differences in scale of timing and size. Our lab has been working on a multi-step culture system to support growth and development of bovine and human oocytes from primordial through to fully grown, using fresh and cryopreserved ovarian cortical tissue. This review outlines the approaches being taken to obtain complete in vitro development of human oocytes and strategies for assessing the health and viability of IVG oocytes.
\end{abstract}

KEY WORDS: Ovary, fertility preservation, follicle culture, cancer

\section{Introduction}

Improvements in chemotherapeutic drugs and regimes has led to improved cancer survival rates and as a consequence increasing attention is now being focused on the long-term adverse effects of these treatments. For young female patients, one of the most important of these is the impact of treatment on fertility. A major consequence of chemotherapy and radiation treatment in young female cancer patients can be ovarian damage which may be manifested as stromal fibrosis and a significant loss of germ cells. Chemotherapy has been shown to result in diminished ovarian reserve, because of its effect on immature (primordial) follicles, leaving cancer survivors at risk of developing premature ovarian failure (POF) resulting in infertility (Anderson et al., 2008). The potential significance of this problem can be illustrated by considering breast cancer which effects just over 1 in 20 women of whom $25 \%$ are pre-menopausal at the time of diagnosis (Del Mastro et al., 2006). The scale of this problem has led to the emergence of Fertility Preservation programmes with the two main preservation strategies being In vitro Fertilisation (IVF) followed by embryo freezing or oocyte freezing with both procedures being carried out prior to chemotherapy. These techniques are not suitable for many women, particularly young girls, and in these cases harvesting and storing of ovarian tissue for future use may be considered. Tissue is harvested as thin cortical biopsies containing mainly immature primordial follicles which are stored after cryo-preservation (Wallace, 2011; Andersen et al., 2012). Storage of ovarian material is being increasingly offered to a variety of patients as a means of fertility preservation (Wallace, 2011; Andersen et al., 2012). At this time the only option to restore fertility using this tissue is by transplantation (Andersen et al., 2012), however, this may not be suitable for all patients because of the potential risk of re-introducing malignant cells (Meirow et al., 2008).

In order to utilise the potential of stored ovarian tissue for restoration of fertility, we need to consider culture systems that can support complete growth of oocytes from early primordial stages through to maturity ex vivo. Whilst the main goal of In vitro Growth (IVG) of oocytes from ovarian biopsies is the production of competent oocytes for assisted reproduction technologies (ART) these methods would also be useful in assessing the viability of cryopreserved ovarian tissue prior to transplantation and therefore, IVG, is key to fertility preservation programmes (Picton et al., 2008;

Abbreviations used in this paper: IVG, in vivo grown; IVM, in vitro maturation; POF, premature ovarian failure.

\footnotetext{
*Address correspondence to: Evelyn E. Telfer. Institute of Cell Biology and Centre for Integrative Physiology, University of Edinburgh. George Square Edinburgh Scotland. e-mail: e-mail: evelyn.telfer@ed.ac.uk
}

Final, author-corrected PDF published online: 5 February 2013.

ISSN: Online 1696-3547, Print 0214-6282 


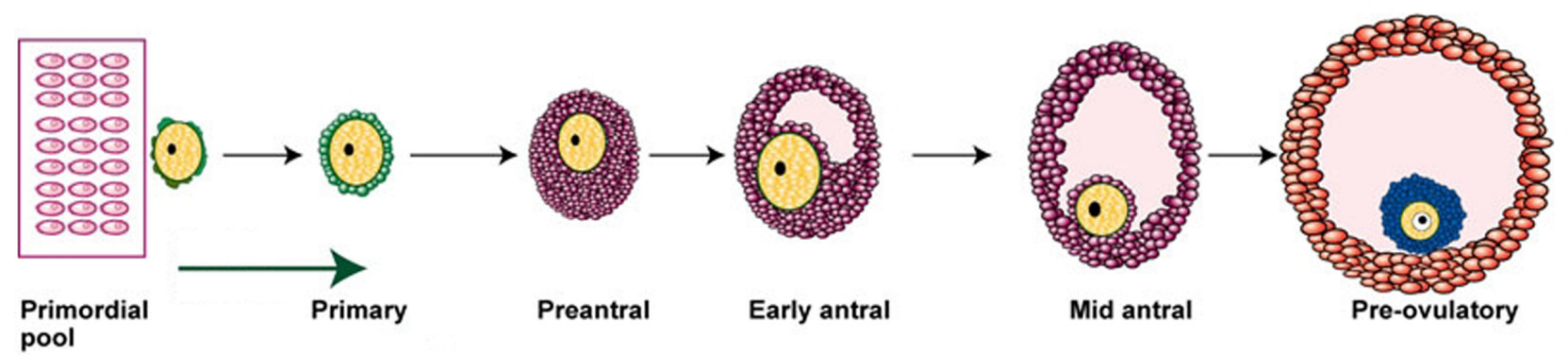

Fig. 1. Representation of the stages of follicle development from the non-proliferating pool of primordial follicles. Primordial follicles are continuously activated into the growing population where they become primary follicles consisting of an oocyte arrested at the dictyate stage of prophase I of meiosis (yellow) surrounded by granulosa cells (green). Primary follicles undergo oocyte growth and granulosa cell proliferation and differentiation (purple) when they form an antral cavity. Antral follicles continue to grow and granulosa cells differentiate into two sub-populations of cells 1) cumulus surrounding the oocyte (blue) and 2) mural lining the wall of the follicle (orange).

Telfer \& McLaughlin, 2011).

Complete oocyte development in vitro from the primordial stage has been achieved in mice (Eppig \& O'Brien, 1996; O'Brien et al., 2003). Early work on this two step culture system resulted in only one live offspring being obtained and this mouse had many abnormalities as an adult (Eppig \& O'Brien, 1996). Following improvements in the technique and after alterations in the culture medium several mouse embryos and offspring have been obtained using IVG combined with in vitro maturation (IVM) and IVF (O'Brien et al., 2003). This work provided proof of concept that complete oocyte development could be achieved in vitro and this has driven the development of methods to be applied to other species, and particularly human. The larger size and longer growth period of human follicles has made the translation of these techniques difficult but progress has been made and we are now able to define conditions that support some stages of human follicle development in vitro (Telfer et al., 2008; Xu et al., 2009; Smitz et al., 2010). These advances bring the prospect of achieving an in vitro system that supports complete human oocyte development closer (Smitz et al., 2010).

In most mammals, oocytes are formed before or shortly after birth and it is believed that there is no significant renewal during adult life (Zuckerman, 1951). The presence of cells that appear to have the potential to form germ cells have been identified in adult ovaries of a range of mammalian species including lemur (David et al., 1974), bats (Antonio-Rubio, 2012), mouse (Zou et al., 2009; White et al., 2012) and human (White et al., 2012). Their physiological role has not yet been determined and so the assumption remains that there is a fixed population of oocytes which are surrounded by somatic cells (granulosa) to form a pool of primordial follicles (Fig. 1).

Whether oocyte renewal can occur or not, the majority of follicles within the ovary in younger women will be at the primordial stage of development and these follicles are continually being utilised during reproductive life (Gougeon \& Chainy, 1987). This population of immature follicles represents an ideal starting population for in vitro growth to obtain fertilisable oocytes for potential use in fertility preservation programmes since it is assumed they have not yet been exposed to selection processes that lead to follicle degeneration (Picton et al., 2008; Thomas et al., 2003). Primordial follicles represent the population of germ cells from which recruitment for growth will take place throughout the woman's reproductive life and this process requires a precisely regulated sequence of events to be initiated. Follicle development can be described as a series of transition stages that start with (1) growth activation of primordial follicles and subsequent development to the multi-laminar preantral follicle, during which time significant oocyte growth occurs; (2) development of an antral cavity at which stage expansion to the pre-ovulatory or Graafian follicle is associated with antral fluid accumulation, granulosa cell proliferation and differentiation into two sub-populations of granulosa cells (cumulus and mural) and (3) rupture of the Graafian follicle releasing a cumulus-oocyte complex at ovulation in response to the mid-cycle LH surge (7) (Fig. 1). Most culture systems are attempting to recapitulate this sequence of events in vitro to achieve oocyte development without necessarily mimicking full follicular development which after antral formation mainly has an endocrine role. Making a good oocyte in vivo is a complicated process and attempting this process in vitro represents an enormous task (Smitz et al., 2010; Thomas et al., 2003; Rodrigues et al., 2008).

During follicular development the oocyte is held in arrest at the dictyate stage of Prophase I of meiosis. The ability to resume meiosis is acquired by the oocyte during follicular growth (meiotic competence) as is the ability to support fertilisation and embryonic development (developmental competence). The development of follicles is regulated by a complex mixture of inhibitory and stimulatory endocrine, paracrine and autocrine signalling by the somatic cells (granulosa and surrounding theca cells) enhanced by a range of oocyte specific regulatory factors mediated through bi-directional communication within the follicle (Rodrigues et al., 2008; Telfer \& McLaughlin, 2011b).

\section{Strategies to support follicle development in vitro}

Various approaches have been taken to support early human follicle development in vitro using fresh (Telfer et al., 2008; Hovatta et al.,1997) and thawed-cryopreserved (Hovatta et al., 1997; Picton \& Gosden, 2000) human cortical tissue. It is clear that to achieve complete in vitro development of human oocytes a multistep culture system is required to support each of the transitional stages (Telfer \& McLaughlin 20011a,b; Telfer et al., 2008; Smitz et al., 2010). The first requirement is to facilitate the initiation of primordial follicle development and support early growth; the second stage is needed to optimise the growth of follicles from preantral to antral stages with completion of oocyte growth being achieved during the third stage. In optimising a culture system the focus needs to be on oocyte development which may not require the development of large follicular structures but rather the maintenance of appropriately differentiated somatic cells in contact with 
the developing oocyte (Fig. 2). The multi-step approach should support the changing requirements of the developing oocyte and its surrounding somatic (granulosa) cells with the main focus being on maintaining oocyte-somatic cell interactions. Much work has been carried out on each of the steps and the challenge now is to put them all together and test the function of the IVG oocytes.

Several groups have worked on each of the steps required to support human oocyte development in vitro: 1) activation of primordial follicles through culturing ovarian cortex (Telfer et al., 2008; Hovatta et al., 1997) 2) isolation and culture of growing preantral follicles to achieve oocyte growth and development (Telfer et al., 2008; Xu et al., 2009; Hovatta et al., 1999; Abir et al., 1997; Roy \& Treacy, 1993). 3) aspiration and maturation of oocyte cumulus complexes (Alak et al., 1998; Cavilla et al., 2008). The aim of our research has been to combine each of the steps to achieve complete oocyte development in bovine (McLaughlin \& Telfer, 2010) and human (Telfer et al., 2008). Fig. 2 illustrates our proposed multi-step IVG system to produce competent oocytes from ovarian cortical tissue and the development of each of these stages will be reviewed.

\section{Activating primordial follicles}

Most viable follicles within ovarian cortical tissue will be at the quiescent primordial stage therefore any IVG system must optimise the activation of primordial follicles in vitro and support early follicle development. The regulation of follicle activation is still unclear but it involves a combination of inhibitory, stimulatory and maintenance factors (Nelson et al., 2012) (Fig. 3). Recent studies involving knock out mouse models have demonstrated the importance of the phosphatidylinositol-3'-kinase (PI3K-AKT) signalling pathway within the oocyte in regulating follicle activation (Fig. 3) (Reddy et al., 2008). The phosphatase and tensin homolog deleted on chromosome ten (PTEN) acts as a negative regulator of this pathway and suppresses initiation of follicle development (Reddy et al., 2008). The transcription factor FOXO3 is a downstream effector of this pathway and acts to inhibit follicle recruitment (Castrillon et al., 2003). Other components of this pathway are dependent on the mammalian target of rapamycin complex 1 (mTORC1), a serine/threonine kinase that regulates cell growth and proliferation in response to growth factors and nutrients and also regulates primordial follicle activation (Adhikari \& Liu, 2010). From knockout mouse data it appears that whilst PTEN within the oocyte suppresses activation of primordial follicles mTORC promotes it (Fig. 3). How these pathways regulate human follicle development is unclear but culture models facilitate the study of these processes. Using pharmacological inhibitors of PTEN in vitro, increased activation of human primordial follicles has been demonstrated (Li et al., 2010). A recent study using a human culture model has also demonstrated that treatment with rapamycin (an inhibitor of $\mathrm{mTORC}$ ) results in decreased activation of primordial follicles but also oocyte loss in growing follicles (McLaughlin et al., 2011). The utility of pharmacological manipulation of these pathways to alter activation rates has yet to be determined but it seems clear that by modifying the tissue environment activation rates can be altered.

Our lab has shown that human primordial follicles can be activated and grow well within mechanically loosened cortical pieces, developing to multi-laminar preantral (secondary) stages within 6 days (Fig. 4 A-E) (Telfer et al., 2008). This system differs from those described in other studies (Hovatta et al., 1997,1999) as the culture medium is serum free and no supporting matrix is present. A key step in this process is tissue preparation which involves removal of most of the underlying stromal tissue and any growing follicles so that the cultured tissue consists of predominantly ovarian cortex containing primordial and primary follicles. When these small fragments of human ovarian cortex are cultured there is a significant shift of follicles from the quiescent to the growing pool over short culture periods of 6 - 10 days (Fig. 4 B,C) (Telfer et al., 2008), an observation repeated in cattle where extensive primordial activation has been reported within 2 days in vitro (McLaughlin \& Telfer, 2010; Wandji et al.,1996, 1997) indicating that activation results from a release from intra ovarian factors that act to inhibit the initiation of follicle growth (McLaughlin \& Mclver, 2009). Cortical strip culture removes follicles from the in vivo endocrine and paracrine processes regulating growth rate; however, follicles will
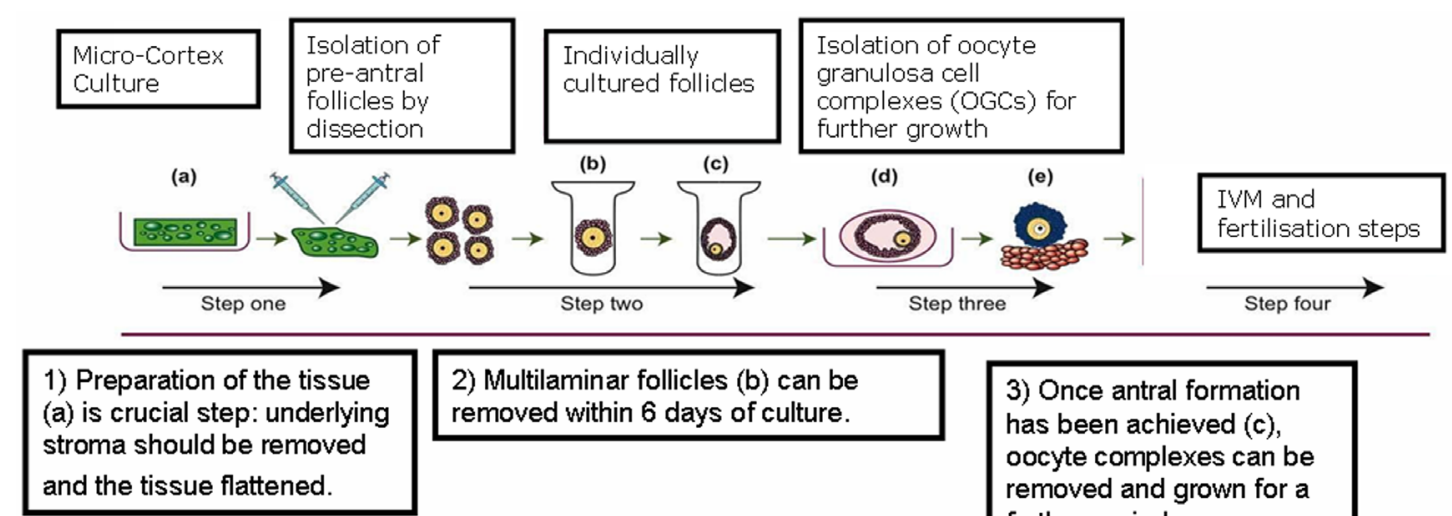

2) Multilaminar follicles (b) can be removed within 6 days of culture.
3) Once antral formation has been achieved (c), oocyte complexes can be removed and grown for a further period.

Fig. 2. Proposed multistep culture system to support complete oocyte development from immature follicles in human cortical biopsies. Steps required to support oocyte development are: activation of primordial follicles within cortical strips. (a) Flattened strips are cultured free floating in medium containing human serum albumin (HSA), ascorbic acid and basal levels of FSH [Telfer et al., 2008]. Once follicles have reached multi-laminar stages they are isolated mechanically using needles and cultured individually as illustrated in (b). (c) Isolated follicle culture to support development from preantral to antral stages (d). The final stages of oocyte growth and development could be achieved by culturing the oocyte and its surrounding somatic cells out with the constraints of the large follicle (e). 
still be subject to the effect of follicle interactions and the influence of stromal cell factors. It is clear that tissue shape and stromal density are important factors that contribute to the regulation of follicle growth initiation in vitro, as solid cubes of cortical tissue show lesser growth initiation (Hovatta et al., 1997) than cortex cultured as flattened "sheets," where much of the underlying stroma is removed (Telfer et al., 2008). The physical environment of the follicles within the cortical tissue affects their response to stimulatory and inhibitory factors and therefore influences their ability to grow (McLaughlin \& Mclver, 2009).

Once follicle growth has been initiated within cortical tissue, follicles can develop to multi-laminar stages. Large multi-laminar follicles do not survive well within the cortical environment and it appears to be inhibitory to further growth resulting in a loss of follicle integrity and oocyte survival (Telfer et al., 2008; Hovatta et al., 1999). Therefore in order to support further development, follicles need to be released from the cortical stromal environment and cultured individually to limit the effect of follicle interactions (Telfer et al., 2008; McLaughlin \& Telfer, 2010).

\section{Preantral-antral development}

The isolation of preantral follicles from cortical tissue post culture can be achieved by mechanical dissection, enzymatic isolation or a combination of both. Enzymatic isolation can be achieved by collagenase and DNase, to remove preantral follicles from stromal tissue and more follicles can be obtained by this method than by mechanical dissection (Telfer, 1996; Park et al., 2005). Collagenase, however can cause damage which leads to poor survival of follicles. Growing follicles need theca layers to retain their structure and to survive the second stage of IVG and collagenase treatment may compromise these layers (Telfer et al., 2000). Some of this damage may be avoided by using new purified enzyme preparations including liberase (Dolmans et al., 2006; Rice et al., 2008). Mechanical isolation using fine needles has the advantage of preserving follicular integrity by maintaining the basal lamina and thecal layers of the follicle but the yield is low

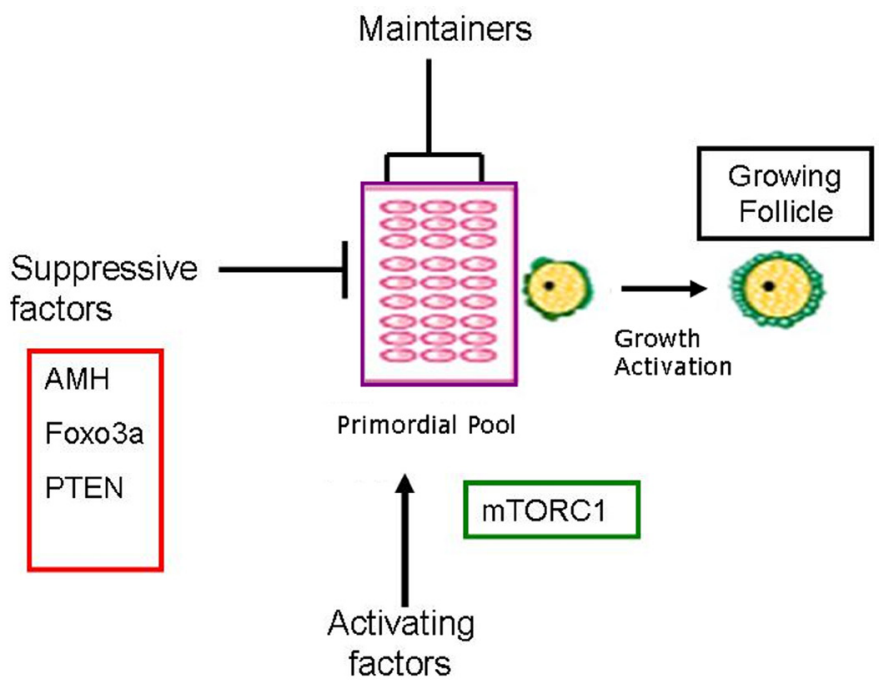

Fig. 3. Regulation of quiescent primordial follicles. A summary of some of the regulatory factors associated with suppressing (red box) or activating (green box) the initiation of growth of primordial follicles. and the procedure slow due to the dense fibrous cortical tissue in human ovaries where follicles are embedded in the tough fibrous cortex and relatively inaccessible (Fig. 4 C,D).

When culturing large mammalian follicles the use of v-shaped micro-well plates has allowed maintenance of three dimensional follicular architecture in vitro whilst promoting growth and differentiation in bovine (Gutierrez et al., 2000; Thomas et al., 2007; Walters et al., 2007) and human follicles (Telfer et al., 2008) with antral formation occurring within 10 days (Fig. 4F). Follicle differentiation has also been reported in bovine follicles embedded in collagen gels and cultured for 13 days (Itoh et al., 1999) and using a combination of media thickened with polyvinylpyrrolidone, a macromolecular supplement and microporous membranes, two live calves have been produced from immature bovine follicles cultured for 14 days (Hirao et al., 2004). In addition to v-shaped micro-well culture plates, follicle encapsulation in alginate hydrogels has been used to support secondary human follicle growth in vitro (Xu et al., 2009) and also rhesus monkey follicles (Ting et al., 2011). Alginate encapsulation is believed to mimic the extra cellular matrix in vivo in terms of its ability to facilitate molecular exchange between the follicle and the culture medium whilst its flexibility can accommodate cell proliferation but its rigidity prevents dissociation of the follicular unit. The rigidity of the alginate capsule affects follicle development as inhibition of growth and reduced steroidogenesis have been reported in murine follicles embedded in $1 \%$ alginate gels (Heise et al., 2005) whereas fully grown human oocytes have been produced using $0.5 \%$ gels (Xu et al., 2009).

The progression of human follicles following isolation from the cortex is remarkable. In the presence of $\mathrm{FSH}$, enzymatically isolated secondary human follicles can differentiate, become steroidogenically active and complete oocyte growth in 30 days (Xu et al., 2009), quiescent follicles activated to grow within cultured fragments of cortex and mechanically isolated as secondary follicles become steroidogenic and undergo differentiation after a 10 day in vitro period with and without activin (Telfer et al., 2008). These observations confirm that local ovarian factors inhibit follicle development in vivo, however, the question remains as to whether the growth rate observed in vitro is accelerated or whether it represents growth without the brakes that are required in vivo to regulate follicle development within the context of the reproductive cycle.The next step is to demonstrate whether the oocytes produced in these systems are capable of in vitro maturation and to determine whether the growth pattern in vitro is deleterious to oocyte function, epigenetic changes and health.

\section{Final stages of oocyte development and in vitro matu- ration}

The ultimate aim of a system supporting follicle growth is to produce competent epigenetically normal oocytes. In order to achieve this, in vitro grown human oocytes need to be matured in vitro. Maturation of oocytes already exists as a separate strategy and is utilised routinely in human assisted reproductive technology processes with varying degrees of success (Nogueira et al., 2012). As discussed earlier achieving and sustaining oocyte growth is the major objective of any complete in vitro development system as this is a size specific indicator of the oocyte's ability to resume meiosis (Fair et al., 1995; Sirard, 2011). The system must also be capable of supporting nuclear maturation and cytoplasmic differentiation 

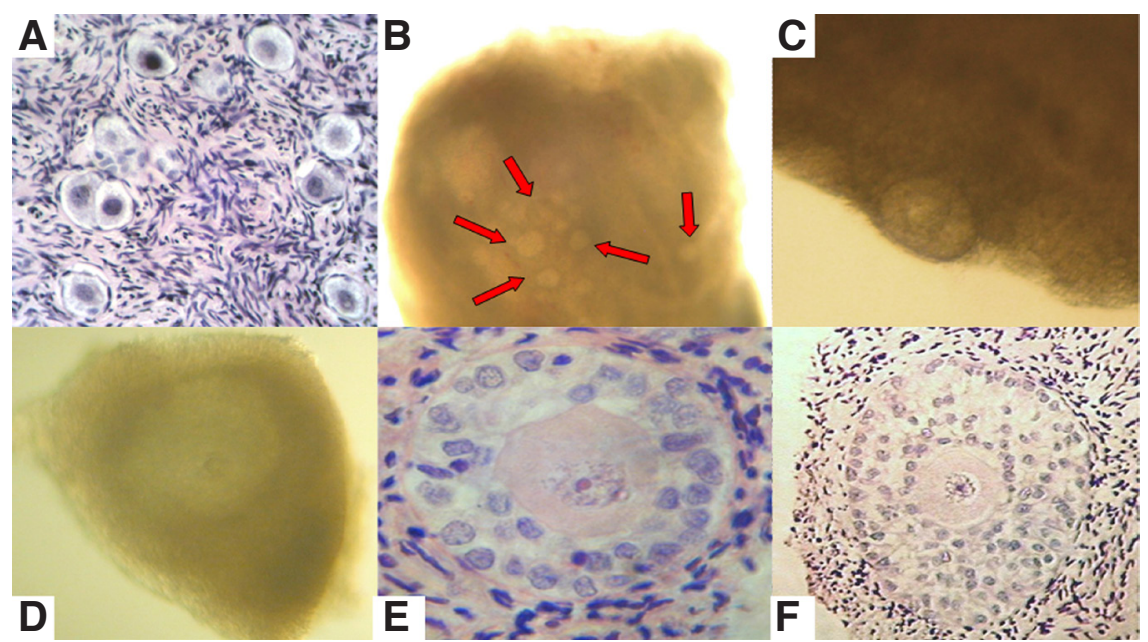

Fig. 4. Photomicrographs of quiescent and growing human ovarian follicles. (A) Primordial follicles in freshly fixed human ovarian cortical biopsy. The majority of follicles within these biopsies are at the primordial stage. (B) Micro-cortex cultured for 6 day showing growing follicles (red arrows) on the surface of the cultured fragment (C) Cultured human ovarian micro-cortex showing a growing follicle protruding from the edge of a fragment after 6 days in vitro. (D) Human in vitro grown (IVG) secondary follicle mechanically dissected with theca layers attached (E) Histological image of a secondary human follicle fixed after 6 days growth within a cortical fragment. (F) Histological section of an in vitro grown human follicle fixed after a total of 10 days of culture showing signs of the start of antral formation.

of oocytes in vitro (Banwell \& Thompson, 2008).

It is widely accepted that whilst $40-80 \%$ of immature human oocytes can successfully complete in vitro maturation and fertilisation giving rise to live births, the rate of maturation of immature oocytes is still well below that of oocytes harvested from stimulated ovaries, indicating that the protocols are sub-optimal or many of the harvested oocytes are intrinsically unable to undergo maturation (Nogueira et al., 2012). In vitro grown oocytes may require a further period of growth within the cumulus complex before maturation (McLaughlin \& Telfer, 2010) (Fig. 2). To achieve this final growth phase the oocyte cannot be considered separately from its companion somatic cells but this oocyte-somatic cell unit needs to be removed from the antral follicle. Maintaining oocyte somatic cell interactions and cytoskeleton stability is important at this stage and in bovine follicles it has been demonstrated that the correct balance of activin and $\mathrm{FSH}$ in vitro affects these processes (McLaughlin et al., 2010).

Oocyte growth within human complexes has been demonstrated in vitro (Cavilla et al., 2008) and live births have been reported using bovine oocyte-granulosa cell complexes which were aspirated from immature follicles and grown for 14 days until the oocyte was large enough to be matured in vitro (Hirao et al., 2004). These results give encouragement that a similar system could be applied to human oocyte granulosa cell complexes aspirated from IVG follicles in order to achieve oocyte diameters suitable to undergo IVM.

\section{The future - making oocytes from germ line stem cells?}

In recent years there have been some exciting and controversial developments in female germ cell biology relating to an increasing body of evidence that shows ovarian follicles may be formed during adult life by a rare population of putative germline stem cells (reviewed Woods et al., 2012; Woods \& Tilly, 2012). Evidence supporting some degree of oocyte renewal during adulthood ranges from morphometry-based studies highlighting the mathematical improbability of a non-renewable oocyte pool being established at birth in rodents (Kerr et al., 2006) to cell depth analysis that indicates that oocytes ovulated from older mice are derived from germ cells that have undergone more mitotic divisions than those that give rise to oocytes in younger females (Reizel et al., 2012; Woods et al., 2012).

The isolation and identification of oocyte-producing germline stem cells, also called oogonial stem cells (OSC), as proof of their existence in ovaries of adult mammals in general, and humans in particular, remained elusive until 2009 when putative germ line stem cells were isolated from adult mouse ovaries (Zou et al., 2009). This study used magnetic cell sorting methods to extract putative germ cell progenitors from dissociated ovaries using an antibody presumed to recognize only germ cells (mammalian vasa homolog Mvh or ddx4), however, doubts were cast on the purity of these cells and whilst this work was encouraging it highlighted the need for improvements in the isolation and purification of such a rare cell type. A recent study addressed these problems and produced a methodology that uses fluorescence activated cell sorting (FACS), rather than the magnetic bead based strategy (White et al., 2012). Using this improved methodology a population of cells have been isolated from adult human and mouse ovaries that can be multiplied in vitro and have been shown to form oocyte-like structures when combined with somatic cells. Identifying cells with apparent germ line potential in the human ovary represents a major development. Clearly these "oocyte-like" cells derived from the progenitor population in vitro require somatic cell support of paracrine and junctional communication to form follicles and develop into functional oocytes. Combining these 'oocyte-like' cells with the human ovarian culture models discussed above may facilitate follicle formation and growth (Telfer \& Albertini, 2012). If oocytes could be derived this way and they proved to be normal this would indeed widen options for fertility preservation.

In conclusion, development of culture systems that support human oocyte development may well offer practical solutions to fertility preservation for many women for whom conventional methods cannot be used but there is still a long way to go before all the relevant testing can be carried out. However, we now have models that we can use experimentally to provide greater insight into oocyte biology and this will aid our progress. Combining these culture models with isolated germ line stem cells would provide a powerful model system that would facilitate the study of processes in humans such as meiosis and genomic imprinting that have previously been experimentally unattainable.

\section{References}

ABIR R, FRANKS S, MOBBERLEY MA, MOORE PA, MARGARA RA, WINSTON RM (1997) Mechanical isolation and in vitro growth of preantral and small antral human follicles. Fertil Steril 68: 682-688. 
ADHIKARI D, LIU K (2010) mTOR signaling in the control of activation of primordial follicles. Cell Cycle 9: 1673-1674.

ALAK BM, COSKUN S, FRIEDMAN CI, KENNARD EA, KIM MH, SEIFER DB (1998) Activin Astimulates meiotic maturation of human oocytes and modulates granulosa cell steroidogenesis in vitro. Fertil Steril 70: 1126 - 1130.

ANDERSEN CY, KRISTENSEN SG, GREVET, SCHMIDT KT (2012) Cryopreservation of ovarian tissue for fertility preservation in young female oncological patients. Future Oncol 8(5): 595-608.

ANDERSON RA, WALLACE WH, BAIRD DT (2008) Ovarian cryopreservation for fertility preservation: indications and outcomes. Reproduction 136: 681- 689.

ANTONIO-RUBIO, NR. PORRAS-GÓMEZ, TJ. and MORENO-MENDOZA, N. (in press) Identification of cortical germ cells in adult ovaries from three phyllostomid bats: Artibeus jamaicensis, Glossophaga soricina and Sturnira lilium. Reprod Fertil Dev DOI: 10.1071/RD12126

BANWELL KM, THOMPSON JG (2008) In vitro maturation of Mammalian oocytes: outcomes and consequences. Semin Reprod Med 26: 162-174.

CASTRILLON DH, MIAO L, KOLLIPARAR, HORNER JW, DEPINHO RA (2003) Suppression of ovarian follicle activation in mice by the transcription factor Foxo3a. Science 301: 215-218.

CAVILLA JL, KENNEDY CR, BYSKOV AG, HARTSHORNE GM (2008) Human immature oocytes grow during culture for IVM. Hum Reprod 23: 37-45.

DAVID GF, ANAND KUMAR TC, BAKER TG (1974) Uptake of tritiated thymidine by primordial germinal cells in the ovaries of the adult slender loris. J Reprod Fertil 41: 447-451.

DEL MASTRO L, CATZEDDU T, VENTURINI M (2006) Infertility and pregnancy after breast cancer: Current knowledge and future perspectives. Cancer Treat Rev 32: 417-422.

DOLMANS MM, MICHAUX N, CAMBONI A, MARTINEZ-MADRID B, VAN LANGENDONCKT A, NOTTOLA SA, DONNEZ J (2006) Evaluation of Liberase, a purified enzyme blend, for the isolation of human primordial and primary ovarian follicles. Hum Reprod 21: 413-420.

EPPIG JJ, O'BRIEN MJ (1996) Development in vitro of mouse oocytes from primordial follicles. Biol Reprod 54: 197-207.

FAIRT, HYTTELP, GREVET (1995) Bovine oocyte diameter in relation to maturational competence and transcriptional activity. Mol Reprod Dev 42: 437-442.

GOUGEON A, CHAINY GB (1987) Morphometric studies of small follicles in ovaries of women at different ages. J Reprod Fertil 81: 433-442

GUTIERREZ CG, RALPH JH, TELFER EE, WILMUT I, WEBB R (2000) Growth and antrum formation of bovine preantral follicles in long-term culture in vitro. Biol Reprod 62: 1322-1328.

HEISE M, KOEPSEL R, RUSSELL AJ, MCGEE EA (2005) Calcium alginate microencapsulation of ovarian follicles impacts FSH delivery and follicle morphology. Reprod Biol Endocrinol 3: 47.

HIRAOY, ITOHT, SHIMIZU M, IGAK, AOYAGI K, KOBAYASHI M, KACCHI M, HOSHI $\mathrm{H}$, TAKENOUCHI N (2004) In vitro growth and development of bovine oocytegranulosa cell complexes on the flat substratum: effects of high polyvinylpyrrolidone concentration in culture medium. Biol Reprod 70: 83-91.

HOVATTAO, SILYE R, ABIR R, KRAUSZT, WINSTON RM (1997) Extracellular matrix improves survival of both stored and fresh human primordial and primary ovarian follicles in long-term culture. Hum Reprod 12: 1032-1036.

HOVATTA O, WRIGHT C, KRAUSZ T, HARDY K, WINSTON RM (1999) Human primordial, primary and secondary ovarian follicles in long-term culture: effect of partial isolation. Hum Reprod 14: 2519-2524.

ITOH T, KACCHI M, ABE H, SENDAI Y, HOSHI H (1999) Growth, antrum formation, and estradiol production of bovine preantral follicles cultured in a serum-free medium. Biol Reprod 67: 1099-1105.

KERR JB, DUCKETT R, MYERS M, BRITT KL, MLADENOVSKA T, FINDLAY JK (2006) Quantification of healthy follicles in the neonatal and adult mouse ovary: evidence for maintenance of primordial follicle supply. Reproduction 132: 95-109.

LI J, KAWAMURAK, CHENG Y, LIU S, KLEIN C, LIU S, DUAN EK, HSUEH AJ (2010) Activation of dormant ovarian follicles to generate mature eggs. Proc Natl Acad Sci USA 107(22): 10280-10284.

MCLAUGHLIN M, BROMFIELD JJ, ALBERTINI DF, TELFER EE (2010) Activin promotes follicular integrity and oogenesis in cultured pre-antral bovine follicles. Mol Hum Reprod 16: 644-653.
MCLAUGHLIN EA, MCIVER SC (2009) Awakening the oocyte: controlling primordial follicle development. Reproduction 37: 1-11.

MCLAUGHLIN M, PATRIZIO P, KAYISLI U, LUK J, THOMSON TC, ANDERSON RA TELFER EE, JOHNSON J (2011) mTOR kinase inhibition results in oocyte loss characterized by empty follicles in human ovarian cortical strips cultured in vitro. Fertil Steril 96: 1154-1159.

MCLAUGHLIN M, TELFER EE (2010) Oocyte development in bovine primordia follicles is promoted by activin and FSH within a two-step serum-free culture system. Reproduction 139: 971-978.

MEIROW D, HARDAN I, DOR J, FRIDMAN E, ELIZUR S, RA'ANANI H, SLYU SAREVSKYE, AMARIGLION, SCHIFF E, RECHAVIG, NAGLERA, BENYEHUDA $D$ (2008) Searching for evidence of disease and malignant cell contamination in ovarian tissue stored from hematologic cancer patients. Hum Reprod 23: 1007-1013.

NELSON, SM. TELFER, EE. and ANDERSON RA. (2013) The ageing ovary and uterus: new biological insights. Hum Reprod Update 19: 67-83. (DOI:10.1093/ humupd/dms043)

NOGUEIRA D, SADEU JC, MONTAGUT J (2012) In vitro oocyte maturation: curren status. Semin Reprod Med 30(3): 199-213.

O'BRIEN MJ, PENDOLA JK, EPPIG JJ (2003) A revised protocol for in vitro development of mouse oocytes from primordial follicles dramatically improves their developmental competence. Biol Reprod 68: 1682-1686.

PARK KS, LEE TH, PARK YK, SONG HB, CHUN SS (2005) Effects of isolating methods (mechanical or enzymatical) on structure of pre-antral follicles in mouse. J Assist Reprod Genet 22: 355-359.

PICTON HM, GOSDEN RG (2000) In vitro growth of human primordial follicles from frozen-banked ovarian tissue. Mol Cell Endocrinol 166: 27-35.

PICTON HM, HARRIS SE, MURUVI W, CHAMBERS EL (2008) The in vitro growth and maturation of follicles. Reproduction 136: 703-715.

REDDY P, LIU L, ADHIKARI D, JAGARLAMUDI K, RAJAREDDY S, SHEN Y, DU C, TANG W, HÄMÄLÄINEN T, PENG SL, LAN ZJ, COONEY AJ, HUHTANIEM I, LIU K. (2008) Oocyte-specific deletion of Pten causes premature activation of the primordial follicle pool. Science 319: 611-613.

REIZEL, Y. ITZKOVITZ, S. ADAR, R. ELBAZ, J. JINICH, A. CHAPAL-ILANI, N. MARUVKA, YE. NEVO, N. MARX, Z. HOROVITZ, I. WASSERSTROM, A. MAYO, A. SHUR, I. BENAYAHU, D. SKORECKI, K. SEGAL, E. DEKEL. N. and SHAPIRO, E. (in press) Cell Lineage Analysis of the Mammalian Female Germline. PLoS Genet DOI: 10.1371/journal.pgen.1002477

RICE S, OJHA K, MASON H (2008) Human ovarian biopsies as a viable source of pre-antral follicles. Hum Reprod 23: 600-605

RODRIGUES P, LIMBACK D, MCGINNIS LK, PLANCHA CE, ALBERTINI DF (2008) Oogenesis: Prospects and challenges for the future. J Cell Physiol 216: 355-365.

ROY SK, TREACY BJ (1993) Isolation and long-term culture of human preantral follicles. Fertil Steril 59: 783-790.

SIRARD MA (2011) Follicle environment and quality of in vitro matured oocytes $J$ Assist Reprod Genet 28(6): 483-488.

SMITZ J, DOLMANS MM, DONNEZ J, FORTUNE JE, HOVATTA O, JEWGENOW K, PICTON HM, PLANCHAC, SHEALD, STOUFFER RL, TELFER EE, WOODRUFF TK, ZELINSKI MB (2010) Current achievements and future research directions in ovarian tissue culture, in vitro follicle development and transplantation: implications for fertility preservation. Hum Reprod Update 16: 395-414.

TELFER EE (1996) The development of methods for isolation and culture of preantral follicles from bovine and porcine ovaries. Theriogenology 45:101-110.

TELFER EE, ALBERTINI DF (2012) The quest for human ovarian stem cells Nat Med 18: 353-354.

TELFER EE, BINNIE JP, MCCAFFERY FH, Campbell B (2000) In vitro development of oocytes from porcine and bovine primary follicles. Mol Cell Endocrinol 163: 117-123.

TELFER, E.E. and MCLAUGHLIN. M. (2011) In vitro growth (IVG) systems for human oocytes: from primordial to maturation. In Principles and Practice in Fertility Preservation (Eds S. Kim and J. Donnez). Cambridge University Press, Cambridge, pp 397-408.

TELFER EE, MCLAUGHLIN M (2011) Human Follicle Activation and Development In Vitro. Semin Reprod Med 29(1): 15-23.

TELFER EE, MCLAUGHLIN M, DING C, THONG KJ (2008) A two step serum free culture system supports development of human oocytes from primordial follicles in the presence of activin. Hum Reprod 23: 1151-1158. 
THOMAS FH, ARMSTRONG DG, CAMPBELL BK, TELFER EE (2007) Effects of insulin-like growth factor-1 bioavailability on bovine preantral follicular development in vitro. Reproduction 133: 1121-1128

THOMAS FH, WALTERS KA, TELFER EE (2003) How to make a good oocyte: An update on in vitro models to study follicle regulation. Hum Reprod Update 9: 1-15.

TING AY, YEOMAN RR, LAWSON MS, ZELINSKI MB (2011) In vitro development of secondary follicles from cryopreserved rhesus macaque ovarian tissue after slow-rate freeze or vitrification. Hum Reprod 26: 2461-2472.

WALLACE WH (2011) Oncofertility and preservation of reproductive capacity in children and young adults. Cancer 117: 2301-2310.

WALTERS KA, CAMPBELL BK, ARMSTRONG DG, TELFER EE (2007) The effects of IGF-I on bovine follicle development and IGFBP-2 expression are dose and stage dependent. Reproduction 131: 515-523.

WANDJI SA., SRSEN V, NATHANIELSZ PW. Eppig JJ, FORTUNE JE (1997) Initiation of growth of baboon primordial follicles in vitro. Hum Reprod 12: 1993-2001.

WANDJI SA, SRSEN V, VOSS AK, EPPIG JJ, FORTUNE JE (1996) Initiation in vitro of growth of bovine primordial follicles. Biol Reprod 55: 942-948.
WHITE YA, WOODS DC, TAKAI Y, ISHIHARA O, SEKI H, TILLY J (2012) Oocyte formation by mitotically-active germ cells purified from ovaries of reproductive age women. Nat Med 18: 413-421

WOODS, DC. TELFER EE. and TILLYJL. (in press) Oocyte Family Trees: Old Branches or New Stems. PLoS Genet DOI: 10.1371/journal.pgen1002848

WOODS DC, TILLY J (2012) The next (re)generation of ovarian biology and fertility in women: is current science tomorrow's practice? Fertil Steril 98: 3-10.

WOODS, DC. WHITE, YA. and TILLY, J. (in press) Purification of oogonial stem cells from adult mouse and human ovaries: an assessment of the literature and a view toward the future. Reprod Sci DOI: 10.1177/1933719112462632

XU M, BARRETT SL, WEST-FARRELL E, KONDAPALLI LA, KIESEWETTER SE, SHEA LD, WOODRUFF TK (2009) In vitro grown human ovarian follicles from cancer patients support oocyte growth Hum Reprod 24: 2531-2540.

ZOU K, YUAN Z, YANG Z, LUO H, SUN K, ZHOU L, XIANG J, SHI L, YU Q, ZHANG Y, HOU R, WU J (2009) Production of offspring from a germline stem cell line derived from neonatal ovaries. Nat Cell Biol 11: 631-636.

ZUCKERMAN S. (1951) The number of oocytes in the mature ovary. Recent Prog Horm Res 6: 63-109. 


\section{Further Related Reading, published previously in the Int. J. Dev. Biol.}

\section{Large-scale production of growing oocytes in vitro from neonatal mouse ovaries}

Arata Honda, Michiko Hirose, Kimiko Inoue, Hitoshi Hiura, Hiromi Miki, Narumi Ogonuki, Michihiko Sugimoto, Kuniya Abe, Mito Kanatsu-Shinohara

Int. J. Dev. Biol. (2009) 53: 605-613

Epigenetic asymmetry in the zygote and mammalian development

Robert Feil

Int. J. Dev. Biol. (2009) 53: 191-201

XIV Workshop on the Development and Function of Reproductive Organs

Massimo De Felici

Int. J. Dev. Biol. (2009) 53: 883-889

Reproductive ageing and the menopause

Colin A. Finn

Int. J. Dev. Biol. (2001) 45: 61-617

In vitro development of growing oocytes from fetal and early postnatal mouse ovaries Maurizio Pesce, Maria Grazia Cerrito, Gabriele Travia, Mario Antonio Russo And Massimo De Felici

Int. J. Dev. Biol. (1996) 40: S229-S230

5 yr ISI Impact Factor $(2011)=2.959$

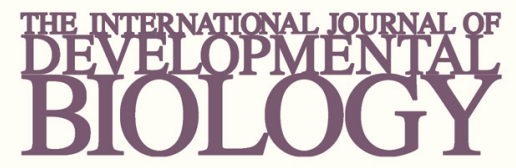

Volume 54 Nos. $6 / 7$
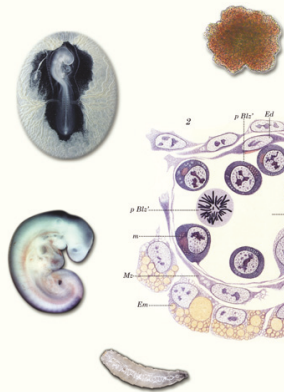

Special Issue

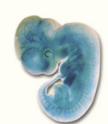

(ㄱ) (3)

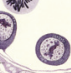

(ㄱ)



$+$
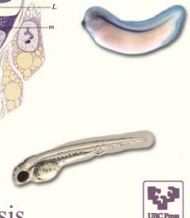

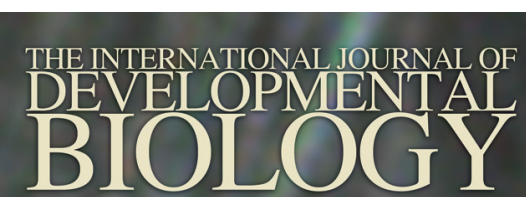

Volume 56 Nos. 1/2/3



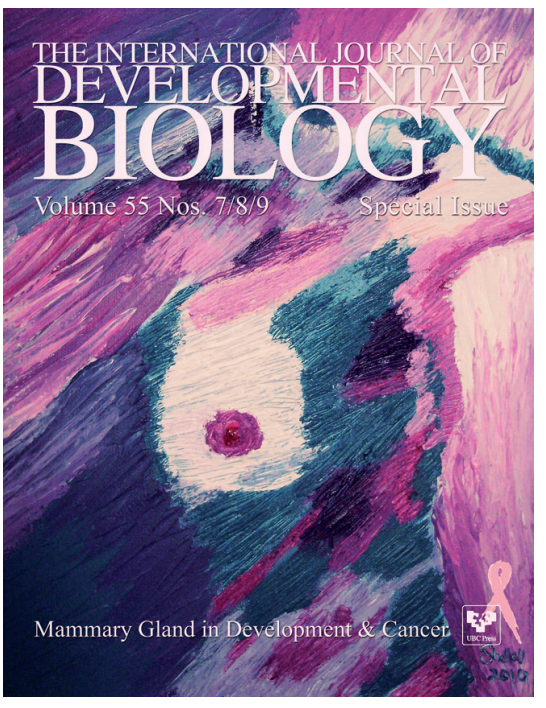

THE INTERNATIONAL JOURNAL OF DEVELOPMENIAI D) $(0)$

Volume 55 Nos. $4 / 5$

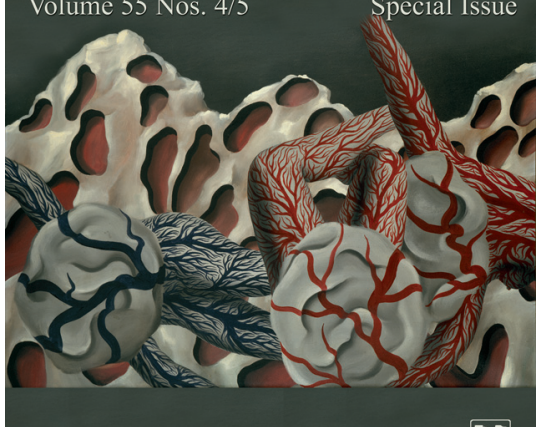

Angiogenesis in Development \& Cance 